\title{
The Enlightenment of New Engineering Concept on the Cultivation of Tourism Information Talents
}

\author{
Yuan $\mathrm{He}^{1, \mathrm{a}}$, Lan Chen ${ }^{1, \mathrm{~b}}$ and Ping Huang ${ }^{1, \mathrm{c}, *}$ \\ ${ }^{1}$ Management School, Chengdu University of Information Technology, Chengdu, Sichuan, China \\ aheyuan@cuit.edu.cn, ${ }^{b} 18782966012 @ 163 . c o m,{ }^{c}$ hping@cuit.edu.cn \\ *Corresponding author
}

\begin{abstract}
Since 2017, under the active promotion of the Higher Education Department of the Ministry of Education and major universities, the new engineering has gradually become a hot topic in recent years. At the same time, with the deep development of tourism, the talents cultivated under the current tourism talent training system of colleges and universities cannot actively adapt to the changes brought about by the changes of the times. The talent quality ability is difficult to meet the industrial development, leading to mismatch between the demand of tourism market and the supply of talents. Therefore, applying the concept of "new engineering" to the process of training tourism information talents, and drawing on new thinking modes to obtain new enlightenment is of great significance for the transformation and innovation of the talent training mode of universities with tourism-related majors. After analyzing the current situation of talent demand and talent training in the tourism market, this paper tries to combine the concept of new engineering with the training of tourism information talents, and then explores a feasible path suitable for the training of tourism information talents.
\end{abstract}

Keywords: new engineering concept, tourism market, tourism informatization talent training

\section{基于新工科理念的旅游信息化人才培养模式重构}

$$
\text { 何源 }{ }^{1, \mathrm{a}} \text {, 陈岚 }{ }^{1, \mathrm{~b}} \text {, 黄萍 }{ }^{1, \mathrm{c}, *}
$$

\footnotetext{
1 管理学院, 成都信息工程大学, 成都, 四川, 中国

aheyuan@cuit.edu.cn, ${ }^{b} 18782966012 @ 163 . c o m,{ }^{c}$ hping@cuit.edu.cn

*通讯作者
}

\section{摘要}

2017 年以来，在教育部高等教育司同各大高校积极推动下，新工科逐渐成为近年来的研究热点话题。 同时, 随着旅游业纵深发展, 当前各高校的旅游人才培养体系下培养的人才还不能积极适应时代变革 所带来的变化, 人才素质能力难以满足产业发展, 导致旅游市场需求与人才培养供给之间还存在错位 的问题。因此将 “新工科” 理念运用到旅游信息化人才培养过程中，借鉴新的思维模式以获得新的启 发对于开设有旅游相关专业的高校的人才培养模式的转型以及创新具有重要意义。本文通过对目前旅 游市场人才需求现状和人才培养问题进行分析后, 尝试将新工科的理念与旅游信息化人才培养进行结 合，进而探索出一条适合旅游信息化人才培养的可行路径。

关键词: 新工科理念, 旅游市场, 旅游信息化人才培养

\section{1. 引言}

新工科正式进入研究者的视野主要是在 2017 年相继推出 的 “复旦共识” [1]、“天大行动” [2]以及 “北京指南” [3] 后, 此时学者们研究的重点是在新经济背景下, 以如何重 点培养新型的、卓越的、有国际化视野的、能够面向产业 需求以及未来发展的高级工程人才, 因此研究所面向的学 科也集中在如何对现有工科进行改造升级和根据产业需 求而新增新兴工科。而在新工科建设过程中, 其理念的运 用已经拓展到工科以外的学科。本文在对新工科相关文献
进行分析后, 将新工科理念概括为以下如下几点:

首先, 有明确的人才培养目标, 即培养出紧跟国家宏观发 展战略、满足产业需求、创新能力强、具有国际视野的、 综合素质全面提高的实践应用型人才, 重视学生的批判思 维、数字化思维、设计思维, 强化学生的生态意识、法制 意识、家国意识, 提高学生的创新创业能力、跨学科交叉 的自主学习能力以及交流沟通能力。在学科专业建设过程 中从三个方向来围绕产业发展进行人才培养: 新型、新生 和新兴, 即 “改存量” 和 “做增量”

其次, 在人才培养体系构建过程中, 学校应以产业动态需 求为基础，以改造传统和发现创新、学科交叉复合、协同 
于时代的需求发展, 多从管理层面进行培养, 导致出现一 种 “什么都学、却什么都不会” 的知识大众化, 竞争力不 强的情况, 真正所学知识难以适应市场发展。[5]

实践培养能力重视不足。现阶段的多数高校重视理论大于 实践, 虽有学校与企业进行合作, 但是重视程度并不明显。 尤其是相对于高职院校,本科院校给予同学们的实训锻炼 机会较少，甚至没有开设自己实训室和实训基地。同时， 期末考试也以理论知识考核为主，一些学生采用 “临时抱 佛脚” 的方式也能蒙混过关, 一方面导致对专业知识掌握 程度不足, 另一方面导致同学们难以将所学运用于实践, 动手能力不强, 毕业后自己所学的知识难以受到企业的待 见, 也消磨了同学们的学习兴趣。

信息化等复合型人才培养不足。[6]旅游专业是一个和其 他行业密切相关的服务型行业,随着旅游信息化纵深化发 展, 旅游企业对旅游人才的要求也进一步提高, 不仅要求 掌握旅游方面的专业基础知识, 同时对电子商务、网站运 营、数据分析、计算机知识以及外语能力等有较高的要求。 但许多院校对于学生应掌握的计算机知识或网站运营能 力重视不足, 偏向培养学生的人文素养和服务意识, 而对 工科思维、逻辑思维培养不足, 而且学生掌握的其他技能 偏少, 创新能力受限, 毕业后难以适应市场需求。

经过上文的分析可以得出以下结论: 目前高校的人才培养 的供给与市场旅游信息化人才的需求还处于错位状态。市 场需要实践能力强, 信息掌握程度高, 有广阔的互联网视 野、能够紧跟时代拥有创新意识的学生, 而高校却重理论 轻实践, 人文素质培养重于理性逻辑思维培养, 且随着信 息化时代发展, 高校依旧保持传统的人才培养模式、教学 体系和课程设置。这导致高校培养出来的人才既不适应市 场需求, 不利于旅游产业未来的发展, 而且不能满足国家 发展战略, 不利于国家经济发展。

\section{3. 新工科理念下旅游信息化人才培养}

\section{1. 市场人才需求现状}

本文通过对去哪儿网、携程、马蜂窝三个公司的线上招聘 职位分析发现, 三个公司主要通过社会招聘和校园招聘的 方式聘用人才, 且两者都要求本科及以上学历。如: 对于 技术类的工作多要求计算机、通信等专业、或有扎实的编 程基础。对于产品类职位多要求金融、统计学、计量经济 学数学等专业优先, 具有较强的数据敏感且能够熟练收集 数据、分析数据和运用数据。对于用户体验类职位要求艺 术设计相关专业, 懂营销运营, 有宽广的互联网视野和时 尚的审美标准。商务支持类职位要求旅游管理专业学生, 编辑类职位要求新闻、广告类专业的学生, 财务类则要求 财务管理类专业的学生, 大型线上高端旅游公司的人才需 求来源多是旅游管理专业以外的学生, 尤其是懂计算机、 数据等拥有专业性技能的学生。因此, 纵观旅游市场, 目 前就旅游信息化角度而言, 市场极为缺乏如旅游软件开发 人才、旅游网站运营人才、旅游营销类人才以及数据运营 等人才等。[4]

\section{2. 高校人才培养现状}

培养目标不明确。目前多数高校在旅游课程设置方面重视 杂而全, 定位于 “全才” 的培养, 且在专业设置方面落后

\section{1. 新工科理念下旅游信息化人才培养目标定 位}

正如上文提到的新工科人才培养的目标 [7], 若将落点定 位到旅游信息化人才培养目标上,即应以立足于培养能够 服务于国家对于旅游业提出的战略性要求的、具有大局意 识和富有时代性的, 能满足信息化智能化背景下旅游新业 态和产业发展需求, 能面向旅游行业的未来发展, 具有创 新思维、能力, 并同时掌握多门技能, 具有跨界整合能力 和高素质的高端旅游信息化人才为目标。只有明确旅游信 息化人才的培养目标, 统筹设计, 整合各方资源, 发挥各 方优势, 才能针对性地培养服务于行业和国家发展的高水 平旅游人才。

\subsection{1. 服务旅游发展战略, 紧跟国家步伐}

自从 2015 年推出旅游 “ 515 ” 战略后, 2017 年国家旅游 局办公室又印发了 “十三五” 旅游信息化规划通知, 在国 家层面的政策持续推动着旅游业的不断发展。“ 515 ” 战略 提出了文明、有序、安全、便利、富民强国的五大发展目 


\subsection{6. 提升综合素质意识, 力求全面培养}

标。推出创新产业促进机制、大力开发新产品新业态、推 进区域旅游一体化、开拓旅游外交、深化旅游体制改革以 及用信息化武装行业等 10 大行动。同时在 “十三五” 规 划中, 提出了到 2020 年实现信息服务集成化、市场营销 精准化、产业运行数据化、行业管理智能化的四大目标。 国家旅游局通过对旅游业发展进行一系列的战略部署, 以 带动国家的整体经济发展。

\subsection{2. 满足旅游产业需求, 弥补市场缺口}

为推进旅游产业在信息化潮流中抓住机遇谋求更好的发 展, 国家 “十三五” 中提出了几大重点建设工程, 如建设 全国全域旅游全息系统工程、民俗客栈信息化工程、旅游 电子商务平台工程、旅游网络营销平台工程、国家旅游基 础数据库提升工程等。在这一系列工程建设过程中必然急 需大量相关人才, 并且这些平台的搭建与信息技术密切相 关, 对旅游专业的学生提出了更严格的标准与更高的要求。 因此, 高校在进行相关人才培养的过程中, 应以满足旅游 产业需求来提高市场匹配度。

\subsection{3. 面向旅游未来发展, 走在时代前沿}

在新工科理念下培养出来的人才面向旅游业的未来发展, 首先各大开展旅游专业的高校必须立足当下, 保持前瞻性 的眼光以预测未来旅游业的发展方向, 走在时代前端, 及 时培养引领旅游业未来发展的具有创新性的卓越人才。这 要求高校应加大旅游研究人才队伍建设, 以学带动术的发 展。同时应及时了解前端高科技技术的发展创新, 从技术 创新中寻找旅游业的发展机遇, 及时把握主动权, 及时更 新课程设置。

\subsection{4. 重视创新创业意识, 追求卓越发展}

创新是推动旅游行业不断向前发展的动力, 是在激烈的市 场竞争中保持优势的重要法宝。拥有了具有创新意识的人 才, 就相当于企业拥有了新鲜血液, 这类人才能够使企业 更具生机和活力。在风云变幻的旅游市场竞争中, 不断创 新、常变常新才能够在众多旅游企业中脱颖而出。所以, 高校在培养旅游信息化人才过程中, 必须重视学生的创新 创业能力, 给他们提供挖掘自身潜力的平台。

\subsection{5. 提高跨界整合能力, “旅游+”跨学科培 养}

“全域旅游”、“智慧旅游” 的进程不断加快, “旅游+” 的模式日渐成熟, 旅游业与各行各业都有一定的关联, 尤 其是在互联网平台上开展的一系列的旅游活动都需要旅 游专业学生不仅需要有扎实的专业基础, 而且要具备跨界 整合能力, 通过构建 “旅游十学科” 的方式, 让学生通晓 行业所需的各种技能与思考方式, 能够拥有全局的眼光, 充分利用各种资源促进行业发展。
旅游行业立足于服务行业, 以为游客提供令其满意, 具有 良好体验的服务为目标。这要求旅游专业的学生应具备基 本的道德素质和职业素质。同时在掌握本专业知识外, 要 具备足够的心理素质、社交能力以及跨专业的其他知识等 综合素质能力。在信息化时代, 各行各业的发展节奏都在 加快, 旅游作为与人们生活息息相关的行业也不例外, 因 此如何在快节奏的时代不断创新、不断完善自己也是对旅 游信息化人才的考验。

\section{2. 新工科内涵下旅游学科建设创新}

在新工科内涵方面,清华大学林健教授将其定位于三个层 面: 新兴、新型、新生。[8]若将其理念运用于旅游学科 建设, 在新兴方面, 高校可思考能否可以根据目前旅游业 发展的变化新创部分专业, 虽然新工科针对的是工科类这 一大类, 而旅游学科针对的是旅游管理、酒店管理等部分 专业, 但若将视野拓展开来, 从旅游产业角度去观察可以 发现, 旅游这一产业链条上涉及多个行业领域, 其包容性 极强加之智能化的背景推动, 如 “智能旅游”、“全域旅游” “虚拟旅游” 等新兴专业, 这同时也符合国家的战略发展 方向。

在新型方面, 随着互联网、物联网、大数据和人工智能技 术等的发展, 顺应时势、把握机遇, 利用这些高新技术来 完成传统旅游业的改造升级是大势所趋。同理, 旅游市场 的发展势必会倒逼开设有旅游专业的高校进行与此相匹 配的人才输送, 也就必须进行相应的人才培养模式的变革, 改进传统的教学体系、课程设置、师资力量建设以及重视 信息化素养等。因此在新工科理念下, 立足新型学科, 促 进传统的人才培养模式转型成为旅游信息化人才培养的 可行路径。

在新生方面, 因为旅游信息化在人才培养过程中所涉及的 知识面是极为广泛的, 如需要计算机编程技术、财务管理、 网络运营等方面的知识技能, 因此可以基于新工科内涵中 学科之间的交叉复合理念来进行新的专业设置进行创新 型人才的培养。如通过与工科、理科、管理、经济、新闻、 医学等学科整合以适应行业发展需要, 如加快推进旅游专 业与计算机专业、电子商务专业、外语专业等学科的融合, 集自身人文特色和工科理科的逻辑思维于一体, 促进学生 的全面发展。

\section{4. 新工科理念下的 “一个导向三个中心” 模式 探索}

通过对新工科理念的总结梳理后, 本文尝试采用了旅游信 息化人才培养过程中的 “一个导向三个中心” 模式。如图 所示, 旅游高校人才培养应以市场需求为导向, 围绕学校、 学科、学生为中心分别进行升级和创新。首先, 学校作为 一个整体与校外旅游企业、高校、研究院以及政府部门共 建育人平台, 学校内部重视师资队伍、课程设置以及实践 应用建设。其次, 学科专业应对自身建设进行升级并与其 他学科融合进行跨学科的交叉复合构建学科间融合培养 的平台。最后以学生为中心, 将旅游市场对学生的要求与 学生职业规划、志趣进行结合, 利用外部推力与学生内部 
动力共同促进自身素质能力提高。

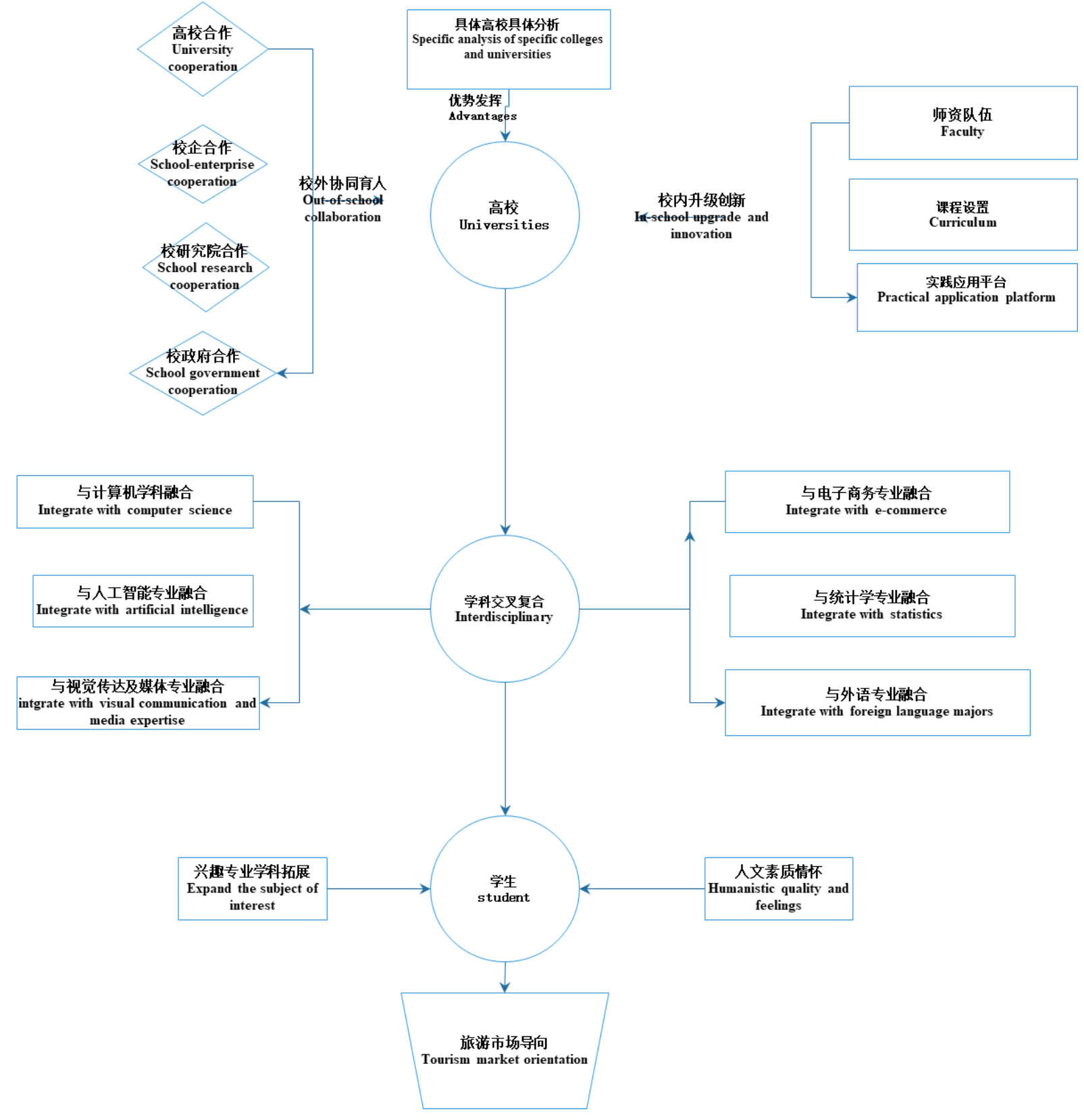

图 1 “一个导向三个中心” 模式图

\section{1. 以旅游市场为导向, 根据需求针对性培养}

各高校都应该以旅游市场为导向, 根据市场动态需求及时 调整学校的教学方案, 学校、学科以及学生三个中心的都 要围绕这一导向建设培养。因此, 高校应该实时了解旅游 市场变化, 老师做好市场调研, 及时整合学科知识, 帮助 学生作职业规划, 树立学习目标, 高校及时发现人才培养 培养问题。将这作为高校人才培养过程中的常态化方式, 对学生而言, 学其所用, 促进就业。对市场而言, 解决市 场人才紧缺状况。

\section{2. 以高校为中心找准定位，促进合作，强化 内部建设}

根据国家文化与旅游部 2018 年 4 月的统计数据, 截至 2017 年, 全国开设旅游管理类本科专业的普通高等院校 有 608 所, 高职类普通高等院校 1086 所, 中职学校 947 所。总计高达 2000 近 3000 所院校开设旅游管理专业。[12] 而在这些院校中, 有工科类院校, 综合类院校, 地方性院 校以及旅游专业性院校。针对不同类型的院校, 在新工科 交叉复合理念下应该发挥各自的特色和优势，立足重点， 有区别的展开。 
其次, 高校要与企业合作, 让同学们走进景区或酒店, 亲 身体验信息化在旅游旅游行业的影响, 实时将理论与现实 结合、与旅游市场接轨。如成都信息工程大学 2017 年老 师带领旅游专业学生前往九寨沟学习,看到了九寨沟由数 字化、信息化、网络化以及景区监控系统等所搭建的 “数 字九寨”。在酒店方面, 学校与万豪集团达成协作, 开办 “万豪班”, 不仅让同学们近距离接触酒店行业, 而且为 同学们的毕业工作提供了机会。

高校与国家旅游相关部门合作,一方面及时了解国家政策 走向, 抓住可利用的机遇促进旅游研究课题向前迈进; 另 一方面利用国家统筹各方资源、发挥各方优势, 为高校的 人才培养提供政策保障, 同时也有利于解决旅游专业学生 的就业难的问题。

高校与旅游研究院合作, 及时了解旅游前沿, 将前沿热点 展现于课堂, 不仅有利于提高学生的创造性意识, 而且有 助于帮助他们及时把握当前旅游发展情况, 对自己的学业 目标确立以及职业规划有更清晰的想法。

\subsection{3. 校内升级, 师资、课程、实践齐建设}

高校可以给老师提供终身学习机会, 让高校老师进入旅游 或酒店企业, 熟悉当下企业需求并掌握相关的旅游实践技 能和管理知识, 再返校将自己所学教授学生, 或是外聘旅 游企业或酒店管理层人员到校授课, 学校根据企业市场需 求及时调整教学方案, 这不仅提高了老师接触市场后对市 场的敏锐洞察力, 使教学紧跟信息时代发展, 也提高了同 学们对旅游行业的浓厚学习兴趣。同时, 高校不应以老师 的学术能力作为单一的衡量标准, 还应将老师的市场实践 经验作为纳入评价体系中。

厦门大学的刘亮军教授在 2018 年提出了新的教学理念指 导以及设置第一第二课堂来提高学生专业能力和跨专业 能力, 以线上线下学习平台和课上课下实践平台来提高学 生自主学习以及实践动手能力 [9]。落实到旅游信息化人 才培养角度, 各高校应重塑旅游人才培养教学理念, 在课 程设置上帮助学生在立足本专业知识的基础上, 明确未来 的就业目标并做好职业规划。同时通过设置第一课堂来提 升旅游专业学生的旅游基础知识和技能, 设置第二课堂来 扩充旅游外的跨专业知识, 如互联网信息技术、电子商务、 市场营销等专业。此外, 充分利用好目前的科学技术, 构 建旅游教学信息化平台,一方面充分利用好目前的线上课 程, 尤其利用好名校的线上高质量课程, 开拓学生的视野 并提高学生的自主学习能力, 另一方面搭建旅游信息化虚 拟仿真实验平台, 提高学生专业学习兴趣和实践动手能力。 此外, 目前多数院校的旅游专业知识期末考核单一, 多局 限于理论知识的考核, 这对于学生来说, 不仅只是将知识 停留于纸面, 而且有些学生甚至采用 “临时抱佛脚” 的方 式侥幸通过期末考试。这并不利于学生知识的吸收, 若要 将信息技术知识真正灌输到学生脑中,可采取实践考核与 理论考核双分制, 通过校企联合的方式, 给同学们增加实 践机会获得实践分数, 无需学生自己外出寻找实践, 通过 实践为学生提供了一个发挥主观能动性的机会。

\section{3. 以 “旅游+”为中心, 促进跨学科交叉复合}

随着科学技术和社会的进步, 旅游行业必然要与社会发展 
而在招聘网站上看到不少企业招聘旅游媒介类人才时,多 偏向新闻传播和汉语言文学专业的学生。虽然这类宣传乃 至文字功底专业知识更扎实, 但他们缺乏旅游专业知识, 对旅游行业的发展乃至旅游者心理等专业性知识是相对 欠缺的。因此在借助媒体来进行旅游宣传时, 只有两者结 合, 即在掌握旅游专业知识的基础上, 提升旅游信息化人 才的媒介素养, 才能让各类层出不穷的媒介为旅游业服务。

\subsection{4. 旅游+电子商务专业}

旅游的在线预定, 无论是酒店、门票预订还是机票车票预 定大多都从线下转移到线上, 微信、支付宝更创造了良好 的支付环境。因此, 如何运用电子商务来发展线上旅游是 当今无法绕开的话题。如成都信息工程大学便专门开设了 旅游电子商务的课程, 并相应的设有实践课程, 让同学们 自己亲手操作酒店景区预订网站的大体造作流程以及如 何开一个旅游类的网店。若要展开更加专业化, 更加深层 次的旅游电子商务, 那么与电子商务专业进行融合不失为 一个好办法。一方面增加了旅游专业学生在电子商务方面 的知识, 另外也拓宽了同学们的视野, 进一步促进旅游信 息化在线旅游的创新。

对于融合措施, 一方面, 学校应该搭建旅游与计算机信息 技术平台, 打破以前的知识条块化, 在学院外再成立团队, 经过专家研究讨论, 如何将计算机信息技术渗透到旅游专 业的学习中, 并同时让同学们在感兴趣的基础上深入学习。 另一方面, 应促进两个专业甚至两个学院的学生进行交 流, 打破部分院校将文科和理工科分在不同校区的做法, 这种做法只会限制学生的通识教育。具体措施如: 可通过 两院共同举办一些旅游创新大赛, 让学生在团队中去感受 信息技术的趣味性。也可不定期组织旅游专业学生进入到 计算机实验室进行参观学习, 旅游专业学生也可为他们提 供外出旅游学习交流的机会, 打破文科工科的隔阂。

\subsection{2. 旅游 + 人工智能类专业}

这两者的融合是旅游业走在时代前端的标志, 而且目前旅 游业和人工智能技术的联系密切程度已显而易见, 如 VR 虚拟技术让旅游者在家也能感受到异地风景的独有的魅 力、景区语音导游等的运用。加之国家目前大力推进人工 智能的发展, 新增人工智能和大数据专业为旅游专业与其 之间的融合提供了良好的契机。

\subsection{3. 旅游+视觉传达及媒体专业}

如与新闻传播专业、视觉传达专业、广告学等融合。因为 旅游信息化的发展过程中, 信息是驱动力, 而传媒行业则 可促进信息的广泛交换传播并拓宽旅游业营销渠道进而 提升旅游企业的营销效果。如充分利用各大媒体, 无论是 新媒体如微博、微信、短视频、直播等还是传统媒体如电 视、广播、报纸等发布旅游相关信息, 提高旅游信息到达 率。甚至可以借助传感器, 大数据以及物联网等进行场景 化信息发布, 了解旅游者在不同空间、时间下的旅游需求 从而提供精准的旅游服务。现在一些城市借助短视频的渠 道宣传城市形象, 据统计, 重庆的宣传短视频的点击率达 百万以上。

\subsection{5. 旅游+ 统计学专业}

通过在前文对旅游人才需求进行分析, 其中有一项学生需 掌握的重要技能即具备对数据敏感性以及分析数据的能 力应该引起重视, 当今乃是一个信息化社会, 在互联网环 境中, 每个用户都是以数字的形式存在其中, 因此他们在 网络平台上留下的痕迹即产生的相关数据则起着至关重 要的作用。因此旅游信息化人才必须具备收集、处理、分 析数据的能力, 培养数据敏感性以及通过数据来把握旅游 者的心理以及预测旅游未来发展趋势的能力。而在学校将 旅游专业与统计学进行融合, 有利于帮助学生提升此方面 的能力。

\subsection{6. 旅游+外语专业}

随着全球化的纵深发展, 各国交流日益频繁, 出入境旅游 日益火热, 根据国家文化和旅游部门 2 月发布的数据, 2018 年, 我国出入境旅游总人数达 2.91 亿人。其中, 出 境旅游人数达 14972 万人, 比上年同期增长 $14.7 \%$ 。[13] 在这个过程中, 旅游人才的外语水平显得尤为重要。一方 面学校可与外国语学院进行合作, 如开展旅游外语大赛, 英、日、韩语进课堂的活动等, 若仅在旅游专业专门开设 几国语言教学课程,一方面学生难以同时接受多语言的学 习, 另一方面对于学校师资而言也是不小的压力。因此可 让学生自主选择一到两门外语, 然后与外国语学院老师对 接, 让他们跟着外国语学院的学生一起学习, 虽不要求达 到与外国语学院同学一样的水平, 但至少足以满足旅游外 语的使用。也可与国外大学进行合作, 为学生提供交流机 会。如成都信息工程大学在 2019 年与韩国东国大学进行 合作, 由学校资助到韩国进行为期一个多月的韩语学习, 酒店观光旅游、国际通商等学习。 


\section{4. 以学生为中心, 促进综合素质全方位提高}

\subsection{1. 兴趣拓展、个性化培养不可忽视}

在学生学习旅游相关知识的同时, 也要促进学生去主动接 触其他学科的知识, 培养学生的自主学习能力, 拓展他们 的就业选择空间。对于旅游管理的学生的而言, 一直以文 科思维为主, 要去学习计算机等其他信息技术学科方面的 思维方式以及生涩的知识可能难以让学生乐意接受。因此 挖掘学生志趣, 将兴趣专业与旅游专业进行结合, 不仅开 拓了旅游的新方向, 更是激发学生动力去学习相关知识。 [10]

\subsection{2. 人文素质、家国情怀不可缺少}

业务能力和知识素质是在当今社会生存的基础, 但并不代 表综合素质培养和人文情怀可以忽略。现如今, “宰客导 游” “黑心导游” 等多次通过媒体曝光进入大众视野, 这 显示了旅游市场还存在混乱的现象。因此作为旅游专业的 学生, 应明白伦理意识、法制意识和生态意识的重要性 [11]。一方面要让学生明白服务行业的核心以及自身作为 大学生因承担的使命, 培养他们家国情怀, 以国际性视野 正确看待旅游业的发展。

\section{5. 总结}

通过从新工科理念中挖掘旅游信息化人才的培养模式路 径, 我们可以分析出以上的人才培养思路, 即在培养能够 服务国家战略、满足旅游产业需求和未来发展、具有创新 创业能力和和跨界整合能力、具备高素质的高端、新型旅 游人才的目标下, 不仅要 “创新变量”, 即对人才培养理 念进行创新, 促进学科间的整合; 同时要 “改存量”, 即 立足传统, 促进原来的教学体系变革升级, 搭建新的组织 架构以服务于人才培养。最后, 每个高校都有自己的发展 特色和主要研究方向, 因此也要具体问题具体分析, 并且 随着国家日益对高校人才培养的重视以及国内高校教育 的提升, 在各大高校中定能探索出一条可行的旅游信息化 人才培养路径。

\section{致谢}

本论文在四川省教育厅 2018-2020 年高等教育人才培养 质量和教学改革重点项目 “基于新工科多学科交叉复合理 念的旅游信息化人才培养实践”和成都信息工程大学教改 课题（JG2018-514）资助下完成。

\section{参考文献}

[1] "New Engineering" Building Fudan Consensus[J]. Advanced Engineering Education Research, 2017(01): 10-11 [ “新工科”建设复旦共识 $[\mathrm{J}]$. 高等工程教育研 究,2017(01):10-11]

[2] "New Engineering" Construction Action Route ("Tian Da
Action") [J]. Higher Engineering Education Research, 2017 (02): 24-25. [ “新工科” 建设行动路线( “天大行动” ) [J]. 高等工程教育研究,2017(02):24-25.]

[3] New Engineering Construction Guide ("Beijing Guide") [J]. Higher Engineering Education Research, 2017 (04): 20-21. [新工科建设指南( “北京指南”) [J]. 高等工程教育研 究,2017(04):20-21.]

[4] HU Xiaocong, Discussion on the Training Mode of Tourism Talents under the Background of "Internet +"[J].Commercial Economy,2015(10):70-71.[胡晓聪. “互联 网+”背景下旅游人才培养模式探讨 [J]. 商业经 济,2015(10):70-71.]

[5] CHENG Ke, Analysis on the Status Quo of Tourism Talent Cultivation and Its Training Mode[J].Journal of Beijing City University,2006(01):100-104.[程柯.旅游人才 培养现状及其培养模式探析 [J]. 北京城市学院学 报,2006(01):100-104.]

[6] ZHANG Yugai, LAN Guiqiu , Problems and Development Countermeasures in the Construction of Tourism Informatization in China [J]. Modernization of Shopping Malls, 2005(18): 47-48. [张玉改,兰贵秋.我国旅游 信息化建设中存在的问题及发展对策 $[\mathrm{J}]$. 商场现代化, 2005 (18):47-48.]

[7] LIN Jian, Future-oriented construction of new engineering in China $[\mathrm{J}]$. Education Research of Tsinghua University, 2017,38(02): 26-35.[林健.面向未来的中国新工 科建设 [J].清华大学教育研究,2017,38(02):26-35.]

[8] LIN Jian, Future-oriented construction of new engineering in China[J]. Education Research of Tsinghua University, 2017,38(02): 26-35.[林健.面向未来的中国新工 科建设[J].清华大学教育研究,2017,38(02):26-35.]

[9] LIU Liangjun, New Engineering: A New Path for Talent Cultivation in Local Undergraduate Colleges [J]. Heilongjiang Higher Education Research, 2018,36.(09): 32-35. [刘亮军.新工科:地方本科院校人才培养的新路径 [J]. 黑龙江高教研究，2018,36.（09）:32-35.]

[10] New Engineering Construction Guide ("Beijing Guide") [J]. Higher Engineering Education Research, 2017 (04): 20-21. [新工科建设指南( “北京指南” ) [J]. 高等工程教育研 究,2017(04):20-21.]

[11] "New Engineering" Construction Action Route ("Tian Da Action") [J]. Higher Engineering Education Research, 2017 (02): 24-25. [“新工科”建设行动路线(“天大行动”)[J]. 高等工程教育研究,2017(02):24-25.]

[12] 2017 年全国旅游教育培训统计.

http://zwgk.mct.gov.cn/auto255/201804/t20180419_832575. html?keywords=

[13] 2018 年旅游市场基本情况.

http://zwgk.mct.gov.cn/auto255/201902/t20190212_837271. html?keywords $=$ 